\title{
HOW TO MEASURE THE IMMEASURABLE DEGREE TO WHICH AN ORGANIZATION IS SUSTAINABLE?
}

\author{
Mazahir, RAZA \\ R\&D Centre, AMA Herbal Laboratories (P) Ltd, Lucknow, India 226017; Email- mraza@amaherbal.com
}

\begin{abstract}
Sustainability improvements can be hard to quantify especially where measurements are not available or the outcomes are insubstantial. Sustainability Indicators can play key role in measure of sustainability .The triple bottom line takes into account three criteria for assessing organizational performance; social or people, environmental or planet and economic, or profit. TBL can used to measure the degree to which an organization is being sustainable.
\end{abstract}

KEY WORDS: Sustainability, triple bottom line, TBL, environment, people, society, 3P

\section{INTRODUCTION}

'Sustainable development is development that meets the needs of the present without compromising the ability of future generations to meet their own needs.'-World Commission on the Environment and Development

For the last decade sustainability has been the main topic of discussion in seminars, conferences and industrial meets. Sustainability means meeting present environmental, social, and economic needs without compromising these factors for future generations. Sustainability is for perpetuity. It is not for X years or generations. Sustainability can also be expressed as greater efficiency in resource use, finally giving benefits to economic growth and overcoming poverty, as well as health and quality of life.

Concerns about sustainability have become increasingly influential in shaping both government policy and the behavior of individuals and businesses. It's no secret our world and business environments are always changing. More than ever, sustainability is key to giving us a competitive edge in today's economy financially, environmentally, and socially. To encourage economic development growth in a sustainable manner the relation between economy, society and environment must be established at grass root level in industry or business community. Many nonprofit organizations (NGOs) are working on theoretical and practical aspects of sustainable business. Ultimately, progressive business leaders started thinking strategically and see sustainability as a catalyst for new business models. Now companies are realizing that for economic prosperity, social wellbeing and environmental protection alignment with NGOs is need for survival in future.

Sustainability is a complex and subjective concept, so in order to measure it, organizations must first define what it means to them and then choose indicators that give the most relevant information about their system and time scale of interest. Now the question is if an organization is growing in sustainable manner then how to measure the degree to which an organization is sustainable. Measuring sustainability is difficult because there is no universal definition and it encompasses many aspects of our society, economy, and governing institutions in addition to our interaction with the natural environment. Since sustainability comprises three interdependent pillars or dimensions: social, economic, and environmental these dimensions can only outline the general scope of a measurement framework.

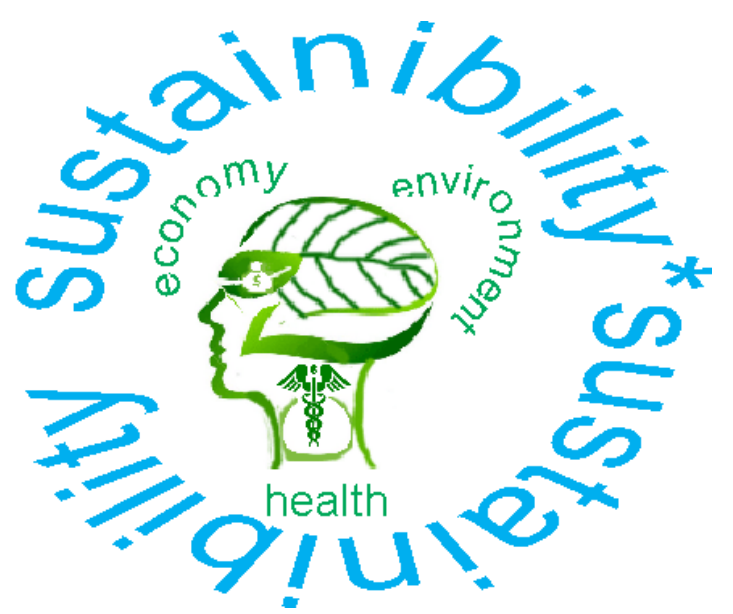

Figure 1. Sustainable cycle

\section{SUSTAINABILITY INDICATORS}

Almost all organizations are familiar with setting goals, performance indicators and metrics. These practices can be applied to sustainability. Sustainability Indicators can play key role in measure of sustainability. Sustainability indicators allow an organization to focus its efforts on specific areas of sustainability and to measure performance. These indicators can help to identify and prioritize sustainability activities of any organization. Indicators can be compiled into indicator systems 
for a more comprehensive result. Indicators, indicator systems and indices can resolve the challenges of measurement of sustainability.

Sustainability indicators are usually derived from available approximate data sources that most closely the qualities people are interested in measuring. For environmental quality it is typically described in terms of air and potable and industrial water quality degree of greenhouse gas emissions, and biodiversity. Economy quality is usually described using macrolevel indicators such as GDP per capita, along with factors such as access to employment, education, and credit, which emphasize the role of individual opportunity. Social equity is measured in literacy rates, infant mortality, health and life expectancy, and crime rates. Indicators that apply to more than one dimension of sustainability can be more holistic; for instance, measuring the quality of a community's waste water treatment and its land-use patterns can help illustrate how environmental quality varies among different areas, providing information about socioeconomic conditions as well as the environment.

Sustainability improvements can be hard to quantify especially where measurements are not available or the outcomes are insubstantial. However the actual numbers are not as important as identifying changes. The use of sustainability indicators is patterned after ecologists' use of indicator species to understand and track ecosystem health and gross trends, rather than precisely documenting natural systems. Sustainability indicators range from estimating the numbers to proxies that can be used to indicate the type and level of change. Although these systems are designed to maximize usage and comparability, a different strategy is to look at sustainability thematically, creating indicator systems designed for specific disciplines or perspectives.

The aim of sustainability indicators is to give organizations enough information to set objective, attainable goals for sustainability and then make evidence-based policy decisions that bring them closer to those goals rather than precisely documenting natural or human systems. There are three basic indicator of sustainability

\subsection{Environmental sustainability indicators}

A business organization already monitors the costs associated with energy and fuel consumption and waste removal or treatment. When organizations invest in efficiency improvement projects it is critical to measure and monitor. Often most savings come from the sum of changes to individual operations or work areas; so it is important to measure and monitor work areas individually. First an organization must identify the right factors measure its starting point monitor whether your improvement activities have made a difference. For an organization it is a uphill task because most of the environmental factors require more complex measurement and calculations. Environmental sustainability indicators include resource consumption rates, loss of energy and/or materials calculated by mass and/or energy balancing, embedded or embodied carbon, direct or indirect emissions converted to carbon dioxide equivalents, quality of air, soil and water, changes in local ecosystems, flora and fauna, , and calculations established by National Pollution Control Body.

\subsection{Social sustainability indicators}

Its not easy to establish social sustainability indicators. Surveys are always found useful to measure the organization's social environment and its reputation in the community. These indicators should cover rate of complains and process of closures, safety and environmental accidents with an impact on the workers and other staff or community as a whole, monitoring of human rights and child labour complaints, customer satisfaction, number of and outcomes from community engagement initiatives and level of contribution to charities or employee days contributed.

\subsection{Economic sustainability indicators}

Almost each and every business has well established financial performance indicators and metrics. Some of these may be defined by financial regulations of government of any state or country. Remaining may be defined by the accounting standard which a company follows such as business efficiency, productivity, Rate of return and payback periods for capital investments customer value, Waste, Inventory turns, Cost of servicing capital, Earnings Before Interest and Tax, Time interest earned, Gross and net profits, Liquidity and other finance management tools.

\section{MEASURING SUSTAINABILITY BY TRIPLE BOTTOM LINE}

In the mid nineties John Elkington worked hard to measure the sustainability by new accounting framework called triple bottom line (TBL). This was developed to include environmental and social dimensions in all calculations in traditional measures of profits and losses. In general, business profit and loss is measured in terms of its economic performance only. A business is considered to be successful only if it has generated a sufficient financial return from its investments, financing activities and operating activities. The triple bottom line takes into account three criteria for assessing organizational performance; social or people, environmental or planet and economic, or profit. TBL refers to an extension of the criteria used to measure the degree to which an organization is being sustainable. In other words Triple bottom line demands that a company's responsibility be to stakeholders rather than shareholders. Stakeholders include anyone who might be affected by a company's or industry's practices, from workers to surrounding communities and beyond. In short Triple-Bottom-Line serves as a conceptual framework to help organizations shape their own socially responsible approaches and it bring numerous opportunities and benefits on its full implementation.

Over the last 30 years academic disciplines organized around sustainability have grown exponentially. According to Andrew Savitz the TBL "captures the essence of sustainability by measuring the impact of an organization's activities on the world including both its profitability and shareholder values and its social, human and environmental capital. People from academia who have studied and practiced sustainability would agree with Andrew Savitz but important is measuring TBL than defining it. The TBL dimensions are also commonly called the 3Ps: people, planet and profits. Economic factors are critical to 
any business and many companies forsee the financial impact from environmental and social issues. Business Houses are being strategic in finding the right balance of investment and benefits across the 'people, planet and profit' aspects of sustainability.

Organizational structure must be designed such way that there must be a sustainability steering body or committee which includes members from board of directors and other top management persons.

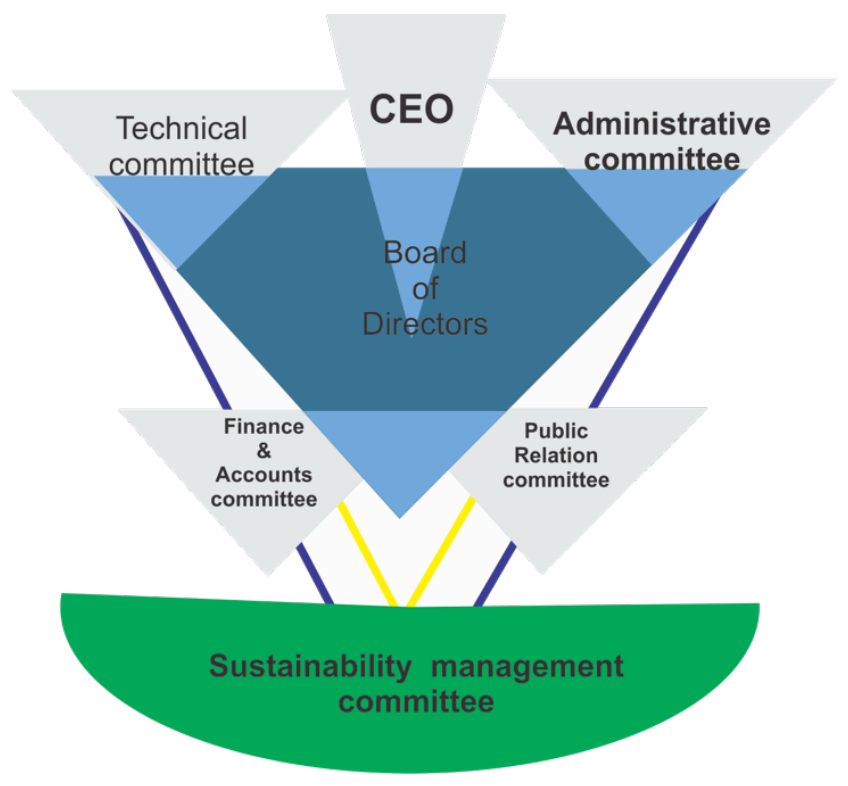

Figure 2. Sustainable organizational structure

\section{HOW TO MEASURE TRIPLE BOTTOM LINE (TBL)}

Each and every thing which is measured has it unit. Since TBL or 3Ps do not have a common unit of measure then how can it be measured? As far profit is concerned it is measured in respective currency of any country. What is the unit in which people or social capital measured? Same with planet or environmental status. Finding a common unit of measurement is one challenge. At present there is neither any universal standard unit nor method for calculating the TBL.

Academia has suggested two methods for measuring TBL .First is monetary calculations and second is in terms of index. It is tough to monetize all the three dimensions of TBL but that would bring advantage of having a common unit, the respective currency of country. When we talk about $3 \mathrm{Ps}$, the first $\mathrm{P}$ which is a profit of a company is the easiest to measure accurately. By traditional methods of accounting monetary value of a company can be determined. By this net worth of any business can be determined at a given point in time. It can also be used to determine the net worth of the business at any point in time.
Now comes second $\mathrm{P}$, the people or social performance of organization, it is somewhat more difficult to judge and measure. This criterion of the TBL takes into account the compound impact that a business has on its employees and a community attached from outside. Here sustainability measurement appears wishy washy because labor wages can be calculated but contribution to living conditions cannot be evaluated in terms of money.

The third $\mathrm{P}$ which is planet, the environmental performance of organization, what impact the total life cycle of product and services of an organization is doing on environment can't be monetized.

Second way to calculate the TBL would be in terms of indices. These are more concise alternative to indicator systems. Index can combine two or more metrics or indicators mathematically to arrive at a single summary indicator. By this way one eliminates the incompatible units issue and, as long as there is a universally accepted accounting method, allows for comparisons between entities, e.g., comparing performance between companies, cities, development projects or some other benchmark.

Some subjectivity remain even when using an index however. For example, How to make an index that is both comprehensive and meaningful and how to identify suitable data for the variables that compose the index? How to weigh the index components? Would each "P" weighed equally? What about the sub-components within each "P"? What is important the people category or the planet? Who decides ? Since sustainability is contextual and lacks a universal definition, there may never be a single common index to measure it. All three dimensions of sustainability cannot be covered in in one index.

An obvious difficulty is covering all three dimensions of sustainability in one index. Today there are five International Sustainability Indices -Ecological Footprint (EP), Genuine Progress Indicator (GP) , Environmental Performance Index (EPI), Human Development Index (HDI and Happy Planet Index (HPI).Both Ecological Footprint and Environmental Performance Index focus on the environmental measures but consider it from different perspectives: EF through the lens of carrying capacity and EPI through that of policy. The Human Development Index (HDI) considers economic and social sustainability but ignores

the environment, whereas the Happy Planet Index (HPI) approximates the environmental costs of human quality of life but ignores the economic costs. Only Genuine Progress Indicator (GPI) somehow covers all three Ps of sustainability but it lacks a standardized methodology and requires a host of assumptions to impute the values of various noneconomic costs. All of these indices vary in scope, from a modish but narrow accounting of the environmental cost of happiness (HPI) to a system that aspires to capture and monetize both internal and external costs and benefits of development (GPI). One possible way to make the most of the available tools is to use them in combination; for example, the FN suggests using EF in combination with HDI. 
Table 2. Summary of Five International Sustainability Indices

\begin{tabular}{l|c|c|c|c|}
\hline Index & Brief description & \multicolumn{3}{|c|}{ Dimension } \\
\hline $\begin{array}{c}\text { Ecological } \\
\text { Footprint }\end{array}$ & $\begin{array}{c}\text { Biocapacity of land } \\
\text { and sea relative to } \\
\text { human demands } \\
\text { mental }\end{array}$ & Yes & no & no \\
\hline $\begin{array}{c}\text { Genuine } \\
\text { Progress } \\
\text { Indicator }\end{array}$ & $\begin{array}{c}\text { Alternative to GDP } \\
\text { that includes } \\
\text { externalized costs }\end{array}$ & Yes & yecial & yes \\
\hline $\begin{array}{c}\text { lvironmental } \\
\text { erformance } \\
\text { Index }\end{array}$ & $\begin{array}{c}\text { Progress of national } \\
\text { environmental } \\
\text { policies }\end{array}$ & Yes & no & no \\
\hline $\begin{array}{c}\text { Human } \\
\text { levelopment } \\
\text { Index }\end{array}$ & $\begin{array}{c}\text { Health, education, } \\
\text { quality of life }\end{array}$ & No & yes & yes \\
\hline $\begin{array}{c}\text { Iappy Planet } \\
\text { Index }\end{array}$ & $\begin{array}{c}\text { Longevity and life } \\
\text { satisfaction per } \\
\text { ecological footprint }\end{array}$ & Yes & no & yes \\
\hline
\end{tabular}

\section{CONCLUSION}

Need of hour is the businesses must pay attention to their use of natural resources and the way in which they impact social welfare. The concept of the triple bottom line means that business success is no longer defined only by monetary gain but also by the impact an organization's activities have on society as a whole. Business concerns must include escalating energy costs, fresh water supplies, global climate change, or all as they factor into the triple bottom line. There is a strong argument that triple bottom line builds sustainable businesses which makes business more profitable and successful .

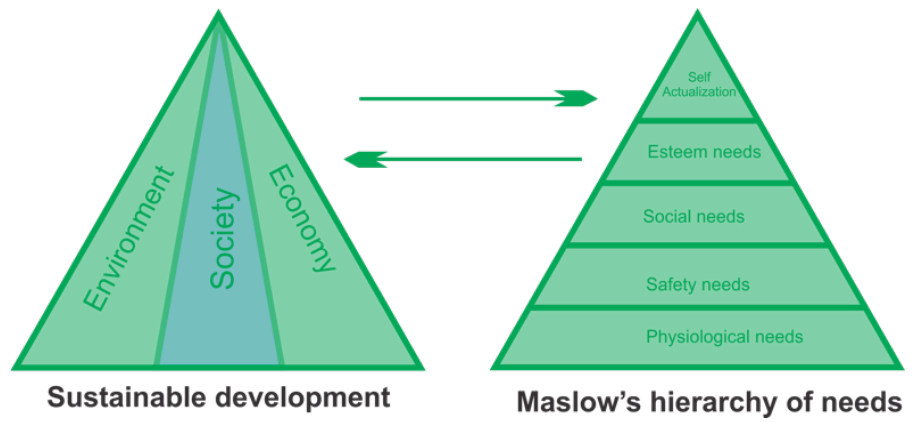

Sustainability Indicators that apply to more than one dimension of sustainability can be more holistic; for instance, measuring the quality of a community's wastewater treatment and its land-use patterns can help illustrate how environmental quality varies among different areas, providing information about socioeconomic conditions as well as the environment. There is one universal difficulty that the indicators that are available are often only a rough approximation of the physical quality being measured. Although the characteristic feature of an indicator is less than ideal accuracy, this imprecision has fed suspicion about the possibilities for measuring sustainability.

Today businesses pursuing sustainability are becoming more efficient, innovative, connected, profitable, and competitive than past business practices. Sustainability measurement tools are concepts that help us to balance the way we successfully run our business and the world that our children's children will inherit from us.

\section{REFERENCES}

1. Andrew Savitz, The Triple Bottom Line (San Francisco: Jossey-Bass, 2006).

29. John Elkington, "Towards the Sustainable Corporation: WinWin-Win Business Strategies for Sustainable Development," California Management Review 36, no. 2 (1994): 90-100.

30. Andrew Savitz, The Triple Bottom Line (San Francisco: Jossey-Bass, 2006).

31. Michael Bloomberg. "Michael Bloomberg Delivers PlaNYC: A Greater, Greener New York," press release, 22 April 2007.

32. Peter Soderbaum, "Positional Analysis and Public Decision Making," Journal of Economic Issues 16, no. 2 (June 1982): 391-400,

33. World Commission on Environment and Development. 1987. Our Common Future. Oxford: Oxford University Press, 43, as cited in International Institute for Sustainable Development, "What is Sustainable Development?" Accessed 19 August 2011.

34. Peter Soderbaum, "Positional Analysis and Public Decision Making," Journal of Economic Issues 16, no. 2 (June 1982): 391-400, www.jstor.org/stable/pdfplus/4225177.pdf.

35. Helen Briassoulis. 2001. "Sustainable Development and its Indicators: Through a (Planner's) Glass Darkly," Journal of Environmental Planning and Management 44:3, 409-27.

36. Simon Bell and Stephen Morse. 2008. Sustainability Indicators: Measuring the Immeasurable? London, UK: Earthscan, 12.

37. Terre Satterfield, Paul Slovic and Robin Gregory, "Narrative Valuation in a Policy Judgment Context," Ecological Economics 34 (2000): 315-331.

38. United Nations Department of Economic and Social Affairs. 2007. Indicators of Sustainable Development: Guidelines and Methodologies. New York: United Nations.

"Compendium: A Global Directory to Indicator Initiatives." International Institute for Sustainable Development website (www.iisd.org/measure/compendium). Accessed 16 May 2011 